DOI: $10.12957 /$ teias. $\%$ Y.55758

\title{
AS METODOLOGIAS ATIVAS COMO POTENCIALIZADORAS DO SISTEMA ATENCIONAL: do presencial ao remoto usando Design Thinking
}

\author{
Cheila Graciela Gobbo Bombana \\ Adriano Canabarro Teixeira
}

\section{Resumo}

Este estudo apresenta a análise das manifestações das funções do Sistema Atencional em estudantes de ensino médio integrado do Instituto Federal do Rio Grande do Sul diante de processos educativos baseados em Metodologias Ativas de Aprendizagem em um contexto de ensino remoto. Desenvolveu-se estudo aplicado, qualitativo e exploratório, tendo como principais referências Pozo (2008) e Bacich e Moran (2018). A pesquisa empírica realizou-se por meio de Intervenção Pedagógica usando os instrumentos: observação, questionário e grupo focal, adaptada do formato presencial para o remoto devido a pandemia de COVID19. Os resultados mostram considerável ativação das funções do Sistema Atencional dos estudantes mediante o uso das Metodologias Ativas de Aprendizagem Sala de aula Invertida e Design Tbinking. A maior influência percebida foi sobre a função do Sistema Atencional Seleção, seguida das funções de Controle e Vigilância. De forma periférica ao foco do estudo foi possível observar a potência de tais metodologias para contextos remotos de ensino. Espera-se que estes resultados impulsionem novas investigações sobre as Metodologias Ativas como estratégias didáticas que estimulem a atenção e favoreçam o aprendizado crítico e reflexivo, mostrando-as como poderosa alternativa neste cenário educacional cada vez mais desafiador.

Palavras-chave: sistema atencional; metodologias ativas de aprendizagem; design thinking.

\section{THE AC'TIVE ME'THODOLOGIES AS PO'T'TENCIALIZERS OF THE ATTENTIONAL SYSTEM: from the presential to the remote using Design Thinking}

\begin{abstract}
This study presents the analysis of the manifestations of the functions of the Attentional System in integrated high school students from the IFRS school in face of educational processes based in Active Learning Methodologies in a remote teaching context. An applied, qualitative and exploratory study was developed, having Pozo (2008) and Bacich an Moran (2018) as main references. The empiric research was carried out through Pedagogical Intervention using the instruments of: observation, questionnaire and focus group, adapted from the presential format to the remote one due to the COVID-19 pandemic.The results show considerable activation of the student's Attentional System functions face the use of Active Learning Methodologies, Inverted classroom and Design Thinking. The biggest noticed influence was on the Attentional Selection System function, followed by the Control and Surveillance functions. Peripherally to the focus of the study, it was possible to observe the potency of such methodologies for remote teaching contexts. It is hoped that these results will impulsionate new investigations on Active Methodologies as didactic strategies that stimulate attention and favor critical and reflective learning, showing them as a powerful alternative in this increasingly challenging educational scenario.
\end{abstract}

Keywords: attentional system; active learning methodologies; design thinking. 


\section{METODOLOGÍAS ACTIVAS COMO POTENCIALIZADORAS DEL SISTEMA DE ATENCIÓN: de lo presencial a enseñanza a distancia utilizando Design Thinking}

\section{Resumen}

Este estudio presenta el análisis de las manifestaciones de las funciones del Sistema de Atención en estudiantes de secundaria de la escuela IFRS frente a procesos educativos basados en Metodologías Activas de Aprendizaje en un contexto de enseñanza a distancia. Se desarrolló un estudio aplicado, cualitativo y exploratorio, teniendo como principales referencias a Pozo (2008) y Bacich y Moran (2018). La investigación empírica se realizó a través de Intervención Pedagógica utilizando los instrumentos: observación, cuestionario y grupo focal, adaptados del formato presencial al remoto por la pandemia de COVID-19. Los resultados muestran una activación considerable de las funciones del Sistema de Atención de los estudiantes mediante el uso de Metodologías Activas de Aprendizaje Aula Invertida y Design Thinking. La mayor influencia percibida fue en la función del Sistema de Selección de Atención, seguida de las funciones de Control y Vigilancia. De forma periférica al foco del estudio, fue posible observar el poder de tales metodologías para contextos de enseñanza a distancia. Se espera que estos resultados estimulen nuevas investigaciones sobre Metodologías Activas como estrategias didácticas que estimulen la atención y favorezcan el aprendizaje crítico y reflexivo, mostrándolas como una poderosa alternativa en este escenario educativo cada vez más desafiante.

Palabras clave: sistema de atención; metodologías activas; Design Thinking.

\section{INTRODUÇÃO}

O processo de aprendizagem na educação formal passa por um momento desafiador diante de tantas mudanças na sociedade. Essas mudanças alteraram significativamente a forma de acesso à informação, as relações humanas e a relação do homem com o conhecimento. Os métodos de ensino que privilegiam a transmissão de informações pelos professores, faziam mais sentido quando $\mathrm{o}$ acesso à informação dependia exclusivamente de intermediários específicos e privilegiados como a Escola, por exemplo.

Para Pozo, "graças a essas novas tecnologias da informação, a escola, em nossa sociedade, já não é a primeira fonte de conhecimento para os alunos e, às vezes, nem mesmo a principal" (2008, p. 23). Tais mudanças do papel da escola demandam novas metodologias de ensino e aprendizagem, capazes de criar um contexto educativo mais relevante e atrativo, que envolva efetivamente o estudante em seu processo de aprendizagem.

Nesta sociedade marcada pela grande quantidade de informações com acesso facilitado, alunos apresentam maior dificuldade em manter a atenção, o que pode prejudicar seu processo de aprendizagem. Segundo o autor espanhol Francisco Mora, um dos principais mecanismos para evocar a atenção "é quando se segue o processo ativo, eficiente, de aprendizagem e memória" (2013, p. 82, tradução nossa). De acordo com o autor, isso está impulsionando a mudança das metodologias educacionais na busca de métodos e recursos capazes que despertar e manter a atenção dos alunos no processo de aprendizagem.

Assim, o estudo realizado justifica-se pela necessidade de identificar estratégias didáticas que possam facilitar o processo de aprendizagem dos alunos, considerando situações de falta de atenção, em especial em uma modalidade remota. Neste contexto surge o interesse pelas Metodologias Ativas de Aprendizagem, que se apresentam como uma alternativa metodológica para tornar as aulas mais engajadoras e o aprendizado mais dinâmico e interativo. 
Cientes da complexidade deste tema, optamos por direcionar nosso estudo para investigar, de maneira específica, os processos de atenção segundo a abordagem do autor Juan Ignácio Pozo. Assim, buscando delimitar nosso tema de estudo, faz-se necessária a melhor compreensão sobre a atenção. Para tal, nos baseamos em Pozo (2008) que define, no contexto do Sistema de Aprendizagem, a atenção como um processo auxiliar, denominado Sistema Atencional que realiza três funções relacionadas: controle, seleção e vigilância.

Nesse sentido, foi possível explorar estratégias didáticas baseadas em Metodologias Ativas de Aprendizagem e investigar a sua influência na manifestação das funções do Sistema Atencional, no contexto dos processos de aprendizagem. Em vista disso, definimos a questão que norteou esta investigação: Quais são as influências de processos educativos remotos baseados em Metodologias Ativas de Aprendizagem sobre o Sistema Atencional de estudantes de ensino médio integrado do IFRS - Campus Sertão?

Assim sendo, o objetivo principal deste estudo foi analisar manifestações das funções do Sistema Atencional em estudantes de ensino médio integrado do IFRS - Campus Sertão diante de processos educativos baseados em Metodologias Ativas de Aprendizagem. Por meio de pesquisa empírica, com abordagem qualitativa do tipo Intervenção Pedagógica utilizando os instrumentos de produção de dados: observação, questionário e grupo focal. A intervenção foi realizada com 8 estudantes do $3^{\circ}$ ano do curso Técnico em Manutenção e Suporte em Informática em 6 encontros, presenciais e remotos.

Cabe salientar que durante a realização da pesquisa empírica, agravou-se no Brasil a pandemia de COVID-19, causada pelo novo coronavírus. Em meados do mês de março de 2020, iniciou-se o isolamento ou distanciamento social como forma de prevenir o contágio pelo vírus. As instituições de ensino públicas e privadas do país anunciaram a suspensão de atividades presenciais por tempo indeterminado. No IFRS todas as atividades letivas presenciais foram suspensas a partir do dia 16 de março de 2020 . Esta situação desafiadora demandou ajustes para a realização do estudo, porém, apresentou-se como uma oportunidade para qualificar a investigação explorando as influências das metodologias ativas sobre o Sistema Atencional no contexto do ensino remoto.

\section{O SISTEMA ATENCIONAL NO PROCESSO DE APRENDIZAGEM}

A aprendizagem requer mobilizar o sistema cognitivo mediante múltiplos processos. Para melhor explicar este ciclo da aprendizagem, Pozo (2008) destaca a importância dos processos auxiliares de aprendizagem: motivação, atenção, recuperação e transferência, e consciência. Para este estudo, focamos na compreensão da atenção e seu Sistema Atencional, cujas funções: controle, seleção e vigilância, são igualmente importantes para despertar, controlar e manter a atenção. Posto que nossos recursos cognitivos são limitados, é preciso selecionar de maneira eficiente onde focálos e evitar que se esgotem, a fim de viabilizar a aprendizagem.

Tendo como objeto de estudo as manifestações das funções do Sistema Atencional em estudantes de ensino médio integrado, buscamos sua melhor compreensão com base nos estudos de Pozo (2008), resgatando de forma resumida as funções controle, seleção e vigilância, mencionadas na introdução deste estudo.

Ao explicar o controle dos recursos atencionais limitados, Pozo (2008) faz a distinção entre processos automáticos e controlados, respectivamente, sem e com atenção. Nos processos controlados ocorre o direcionamento da atenção, que acontece de modo coordenado, de forma 
que o indivíduo diante dos estímulos de um ambiente mantenha sua atenção concentrada em determinada atividade.

A função de seleção funciona como um filtro, ou seja, diante de todo o bombardeio de estímulos a que somos submetidos a cada instante, para onde decidimos direcionar nossa atenção. Pozo enfatiza que "nem todos os estímulos e informações chamam a atenção igualmente, costumamos dar mais atenção à informação interessante, a que tem a ver com nossa motivação" (2008, p. 148) .

Nem sempre, despertar a atenção é o mais difícil, mas sim, mantê-la por longos períodos. A função de vigilância é a responsável por essa atenção contínua, é a parte do sistema atencional que nos mantém atentos e alertas, concentrados em uma atividade por períodos longos. Porém, quando a atividade requer uma atenção contínua prolongada, como acontece com a maior parte das aprendizagens complexas, essa pode ser uma tarefa bem difícil.

De acordo com Pozo (2008), as três funções do sistema atencional (controle, seleção e vigilância) podem se tornar mais efetivas na aprendizagem se os professores adotarem estratégias metodológicas que facilitem a manifestação destas funções. Para tal, o autor sugere alguns princípios nos quais os professores podem basear sua intervenção:

1.Selecionar a informação, discriminando o relevante ou principal do secundário, e utilizar sinais para destacar o mais relevante do acessório, com o fim de atrair a atenção dos alunos. [...] 2. Apresentar os materiais de aprendizagem de forma interessante, tanto na forma como no conteúdo, levando em conta as motivações dos alunos. 3. Graduar a apresentação de informação nova que deva ser aprendida, de forma que não se tenha de prestar atenção a muitas coisas novas ao mesmo tempo [...] 4. Automatizar operações, conhecimentos e processos, de forma que deixem de consumir recursos atencionais [...] 5. Dosar as tarefas, evitando que sejam muito longas ou complexas, de forma que não exijam uma atenção contínua, que canse em excesso os alunos. 6. Diversificar as tarefas de aprendizagem, mudando o formato e envolvendo ativamente os alunos na execução das mesmas. É preciso evitar cair na monotonia [...]. (p. 150).

Conhecendo o importante papel da atenção do processo de aprendizagem precisamos pensar em estratégias didáticas que possam favorecer sua ativação. Neste sentido, Pozo sugere que "mudar as rotinas, diversificar as tarefas de aprendizagem, fazer com que as tarefas sejam sempre distintas e imprevisíveis é uma forma eficaz de atrair e, principalmente, de manter a atenção dos alunos" (2008, p. 149). Assim, percebemos que a monotonia didática pode ser uma grande inimiga da atenção, prejudicando consideravelmente a aprendizagem.

\section{METODOLOGIAS ATIVAS DE APRENDIZAGEM}

Tendo em vista o objetivo de nossa pesquisa, buscamos aprofundar conhecimentos sobre as Metodologias Ativas de Aprendizagem, compreendendo seus princípios e práticas, de modo a contribuir para a escolha das metodologias e tecnologias digitais utilizadas no desenvolvimento da pesquisa empírica.

Metodologias Ativas de Aprendizagem, de acordo com Bacich e Moran, "são estratégias de ensino centradas na participação efetiva dos estudantes na construção do processo de aprendizagem, de forma flexível, interligada e híbrida [...] expressam-se por meio de modelos de ensino híbridos, com muitas possíveis combinações". (2018, p. 4). Tais metodologias, consideram 
uma perspectiva de aprendizagem ativa e são norteadas pelos seguintes princípios: o aluno como centro o processo de aprendizagem; o professor como mediador, facilitador, ativador; autonomia; reflexão; problematização da realidade, trabalho em equipe e inovação.

O desenvolvimento das Metodologias Ativas de Aprendizagem pode ser auxiliado por Tecnologias Digitais, para facilitar a aproximação da realidade em que os alunos estão imersos, favorecendo a interação e o envolvimento dos estudantes com o processo de aprendizagem. Acerca desta possibilidade, Bacich e Moran enfatizam que:

A combinação de metodologias ativas com tecnologias digitais móveis é hoje estratégia para a inovação pedagógica. As tecnologias ampliam as possibilidades de pesquisa, autoria, comunicação e compartilhamento em rede, publicação, multiplicação de espaços de e tempos; monitoram cada etapa do processo, tornam os resultados visíveis, os avanços e as dificuldades. (2018, p. 12).

Tais abordagens, enriquecidas por tecnologia, caracterizam o Ensino Híbrido. $\mathrm{Na}$ concepção de Bacich (2015), o ensino híbrido é uma das tendências da Educação do Século XXI, pois promove uma integração entre o ensino presencial e propostas de ensino online visando a personalização do ensino. Para efetivação do Ensino Híbrido, a Sala de Aula Invertida é uma metodologia ativa que merece destaque.

No modelo chamado de Sala de Aula Invertida, os estudantes aprendem em casa por meio de cursos e aulas online, e os professores usam o tempo de aula para práticas ou projetos orientados. Conforme Christensen, Horn e Staker (2015), no modelo da Sala de Aula Invertida “o período de sala de aula torna-se um tempo de aprendizagem ativa, que milhares de estudos de pesquisa sobre aprendizagem indicam ser muito mais eficaz do que a aprendizagem passiva". (p.43).

Indo ao encontro de nosso objetivo principal, exploraremos também a abordagem Design Thinking como possibilidade metodológica para ser integrada ao modelo Sala de Aula Invertida nos encontros síncronos. Por ser uma "sistemática que tem como objetivo gerar e aprimorar ideias, facilitando o processo de solução dos desafios cotidianos com criatividade e de forma colaborativa" (BACICH; MORAN, 2018, p.15), apresenta-se como possibilidade metodológica potencializadora do Sistema Atencional no processo de aprendizagem.

Figura 1: Fases do processo Design Thinking

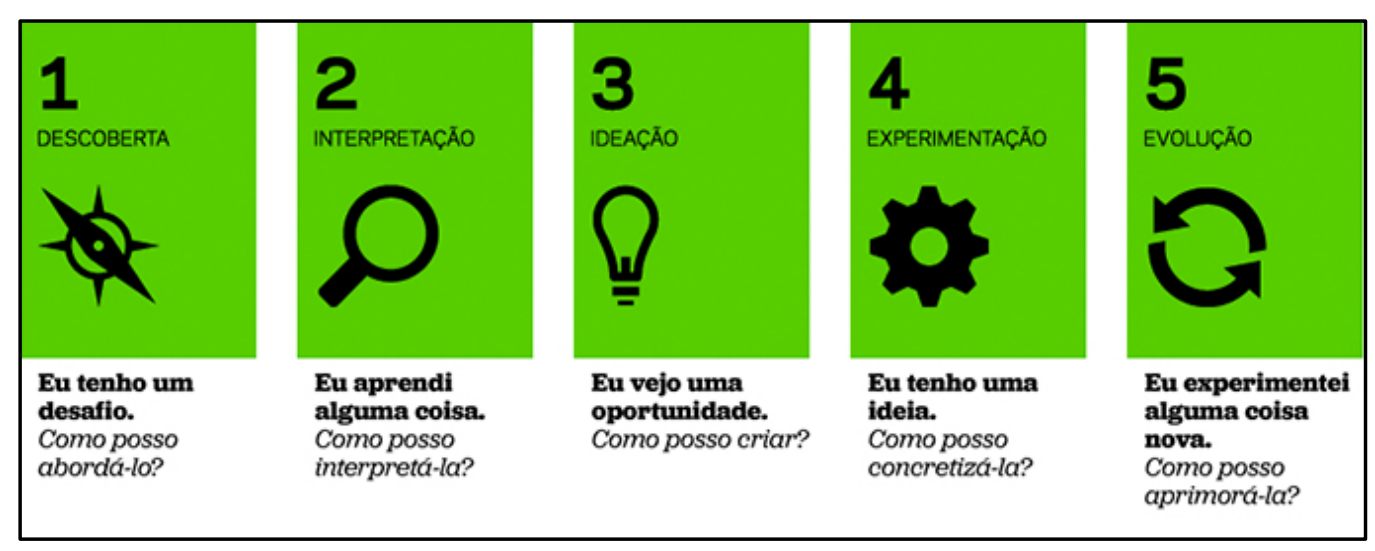

Fonte: adaptado pelos autores de Instituto Educadigital (2014).

As cinco fases do processo: descoberta, interpretação, ideação, experimentação e evolução, ilustradas na Figura 1, junto aos questionamentos que ajudam a compreendê-las, orientam o 
desenvolvimento da abordagem, permitindo identificar um desafio e construir a solução para ele. De acordo com Rocha (2018), "as etapas do design thinking reúnem métodos da engenharia e do design, combinados com ideias originadas das artes, procedimentos das ciências sociais e insights do mundo dos negócios". (p. 161). O processo do Design Thinking permite gerar e aprimorar ideias de forma estruturada.

Assim percebemos a combinação da Sala de Aula Invertida com o Design Thinking, como alternativa metodológica interessante para favorecer a ativação do Sistema Atencional em processos de aprendizagem. Visto que os momentos online podem ser dedicados para a apropriação do material de apoio necessário ao desenvolvimento de cada fase da abordagem, já nos momentos de encontros, professores e alunos podem direcionar sua atenção controlada para as desafiadoras e complexas atividades de resolução de problemas.

\section{MÉTODO}

Este estudo classifica-se como pesquisa qualitativa de caráter exploratório e natureza aplicada. Quanto aos procedimentos, optou-se pela pesquisa do tipo Intervenção Pedagógica, pelo seu caráter aplicado e finalidade de contribuir para a solução de problemas práticos, também por apresentar-se como importante método para a Educação.

Figura 2: Desenho da Pesquisa

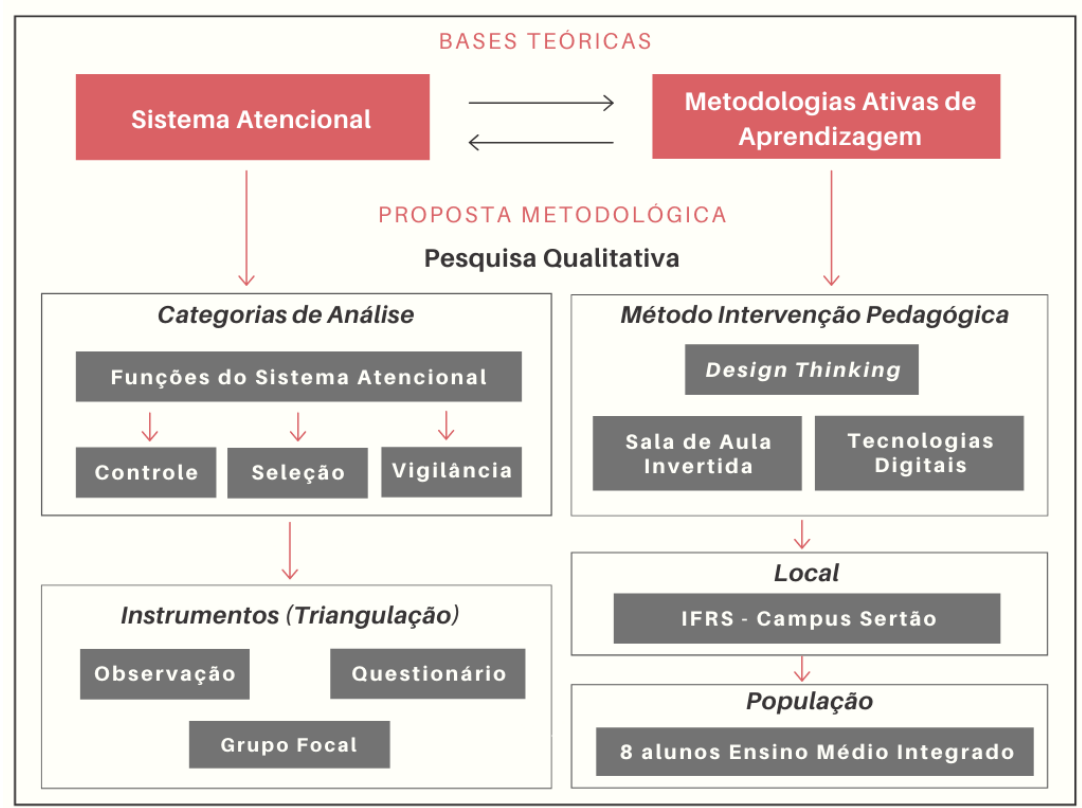

Fonte: autores (2020).

A Figura 2 ilustra o resumo da proposta metodológica, mostrando as escolhas realizadas, os principais elementos que compõe a metodologia deste estudo e o fluxo de construção da proposta. Esta pesquisa foi submetida ao Comitê de Ética da Universidade de Passo Fundo, conforme CAAE nr. 22916319.4.0000.5342 e aprovada por meio do Parecer Consubstanciado nr. 3.671.473 em 30 de outubro de 2019. 


\section{Local e População}

A pesquisa foi realizada com alunos da turma do $3^{\circ}$ ano do curso Técnico em Manutenção e Suporte em Informática, na disciplina Projeto Integrador III. Durante a realização da pesquisa de campo, a pandemia de COVID-19 provocou a suspensão das atividades letivas no IFRS. Com a suspenção do Calendário Acadêmico da instituição e a impossibilidade de realização de encontros presenciais houve uma redução da população inicial da pesquisa, desse modo, a investigação foi concluída com a participação efetiva de 8 estudantes.

\section{Categorias de Análise e Instrumentos}

A análise dos dados teve como embasamento as 3 (três) categorias de análise: Controle, Seleção e Vigilância, conforme Figura 2, que são as funções do Sistema Atencional selecionadas com base na obra de Pozo (2008). Estas categorias foram subdivididas em 9 (nove) subcategorias de análise, apresentadas na Tabela 1, que representam as manifestações das funções do Sistema Atencional. Lembrando que a escolha dessas categorias de análise ocorreu em consonância com o objetivo principal desta pesquisa.

Tabela 1: Categorias de Análise de Dados

\begin{tabular}{|c|c|c|c|}
\hline \multicolumn{2}{|c|}{ Categorias de Análise } & \multicolumn{2}{|c|}{ Subcategorias de Análise } \\
\hline Id. & $\begin{array}{c}\text { Funções do } \\
\text { Sistema Atencional }\end{array}$ & Id. & Manifestações das funções do Sistema Atencional \\
\hline \multirow{3}{*}{ CA 1} & \multirow{3}{*}{ Controle } & CA 1.1 & Concentração na tarefa \\
\hline & & CA 1.2 & Realização de tarefa em série \\
\hline & & CA 1.3 & Esforço intencional consciente para realizar tarefa \\
\hline \multirow{3}{*}{ CA 2} & \multirow{3}{*}{ Seleção } & CA 2.1 & Escolha de estímulos mais importantes para focar atenção \\
\hline & & CA 2.2 & Escolha de elementos diferentes/novos para focar atenção \\
\hline & & CA 2.3 & Direcionamento da atenção às tarefas e ao professor \\
\hline \multirow{3}{*}{ CA 3} & \multirow{3}{*}{ Vigilância } & CA 3.1 & Manutenção da atenção às orientações sobre a tarefa \\
\hline & & CA 3.2 & Manutenção da concentração na tarefa por longo período (30 minutos) \\
\hline & & CA 3.3 & Não dispersar a atenção com frequência \\
\hline
\end{tabular}

Fonte: autores (2020).

Para a produção de dados foi utilizada a técnica de triangulação, por meio da combinação dos instrumentos observação participativa, questionário e grupo focal. Para a produção dos dados e posterior análise foram elaborados e aplicados Protocolo de Observação, Questionário por meio Google Formulários e Roteiro para Grupo Focal, detalhados a seguir.

O Protocolo de Observação foi elaborado em forma de lista de verificação, contendo as seguintes informações: observador, data, duração e local do encontro, fase do Design Thinking e 
nove situações a serem observadas, correspondentes às subcategorias de análise apresentadas na Tabela 1. O preenchimento dos protocolos foi realizado a partir da observação participativa e posterior verificação das gravações em vídeo, feitas nos encontros presenciais, e das gravações realizadas nos encontros remotos por meio da ferramenta Google Meet.

O Questionário com perguntas abertas e fechadas, também norteadas pelas subcategorias de análise já elencadas, foi respondido pelos alunos participantes ao final da pesquisa apresentando suas percepções sobre a manifestação da atenção e sobre as metodologias utilizadas na intervenção. Para facilitar a distribuição e aplicação do questionário, também posterior formatação e análise dos dados, optamos pela criação de um formulário digital usando o Google Formulários.

Para a realização do Grupo Focal foi elaborado e aplicado roteiro com um conjunto de perguntas abertas, alinhadas com as categorias de análise deste estudo, a fim de estimular discussões e opiniões do grupo. Esse instrumento foi utilizado como ferramenta de validação, por ser mais flexível e permitir análises baseadas em discussões abertas, possibilitou elucidar discrepâncias entre os dados produzidos por meio da observação participativa e do questionário respondido pelos estudantes.

\section{Método da Intervenção}

Em consonância com nosso tema de pesquisa, tomamos como base para planejamento da intervenção as Metodologias Ativas de Aprendizagem, de maneira específica, a abordagem Design Thinking combinada com a Sala de Aula Invertida. Na elaboração do plano para a intervenção pedagógica foram considerados os princípios para ativação do Sistema Atencional bem como a utilização de Tecnologias Digitais conforme suas possíveis contribuições para as atividades propostas.

\section{Figura 3: Sistematização do Método da Intervenção Pedagógica}




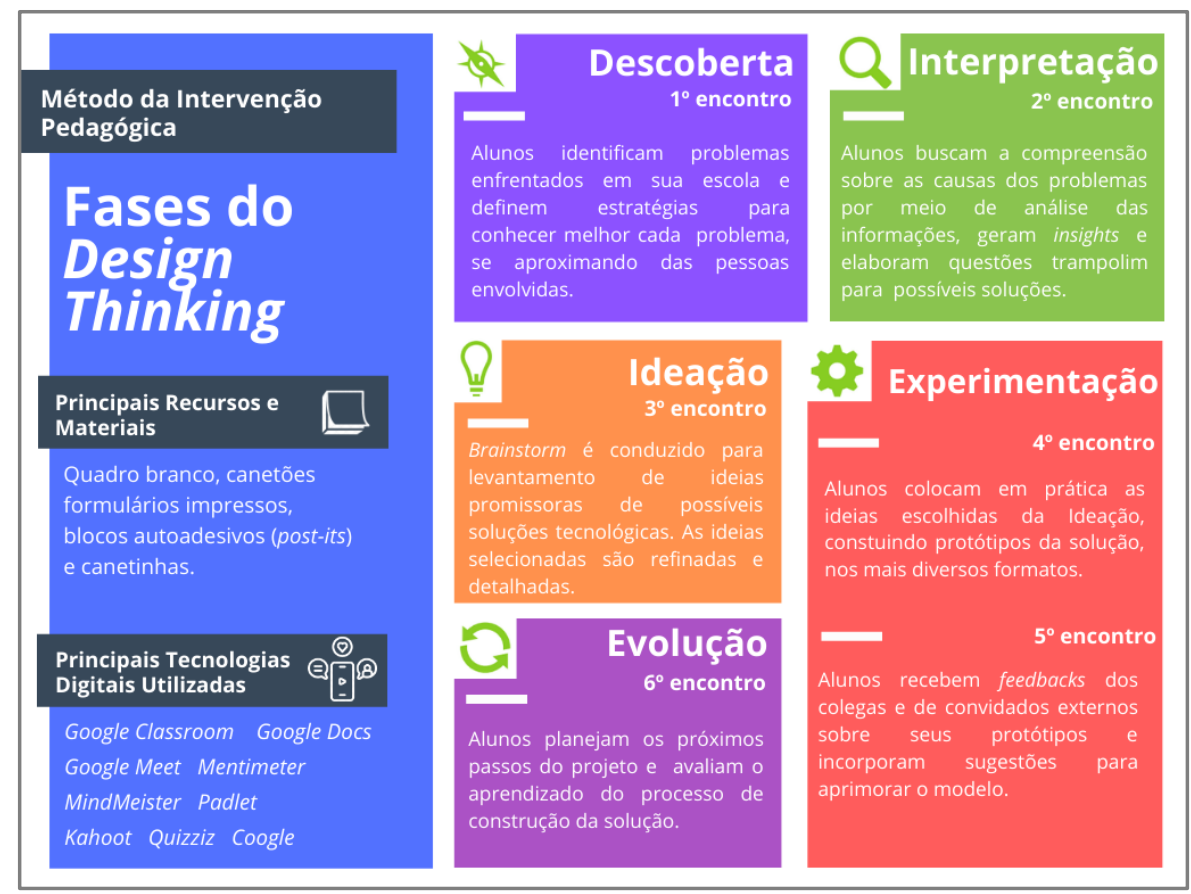

Fonte: autores (2020).

O Método da Intervenção Pedagógica, ilustrado na Figura 3, foi elaborado com base, principalmente, no manual Design Thinking para Educadores (2014) e contempla as cinco fases do processo: descoberta, interpretação, ideação, experimentação e evolução, realizando as adaptações necessárias de acordo com o contexto de realização da pesquisa.

\section{RELATOS DA EXPERIÊNCIA E ANÁLISE DOS RESULTADOS}

A pandemia causada pelo novo coronavírus provocou a suspensão de todas as atividades letivas presenciais no IFRS a partir do dia 16 de março de 2020. Com isso, houve a necessidade de adaptação do método da intervenção pedagógica. Em vista disso, parte da pesquisa de campo aconteceu em formato híbrido e outra parte em formato totalmente remoto.

A Figura 4 sintetiza, de forma sequencial, as adaptações realizadas no método da Intervenção Pedagógica a fim de possibilitar sua realização em formato remoto, levando em consideração as limitações e possibilidades deste novo contexto de realização da pesquisa empírica.

\section{Figura 4: Plano Atividades Remotas}




\section{Intervenção Pedagógica}

\section{PLANO ATIVIDADES REMOTAS}

Adaptação das atividades devido a suspenção das aulas presenciais

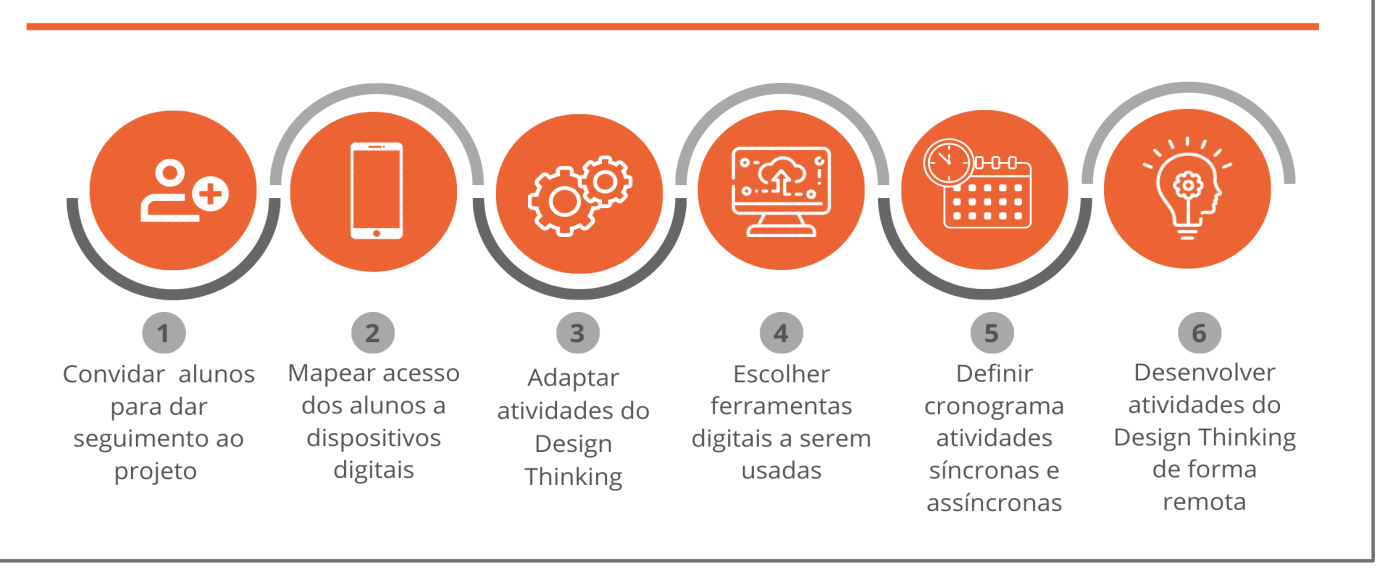

Fonte: autores (2020).

A intervenção pedagógica foi realizada em dois encontros presenciais e quatro encontros remotos. Os encontros presenciais aconteceram no mês de março de 2020 com duração aproximada de 4 horas. Esses encontros foram realizados no IFRS - Campus Sertão, em sala de aula e no laboratório de informática. Os encontros remotos aconteceram no mês de maio de 2020, com duração média de 1,5 horas cada encontro por meio do serviço de comunicação por vídeo Google Meet.

A implementação da modalidade Sala de Aula Invertida combinada à abordagem Design Thinking foi realizada utilizando diversas ferramentas digitais, entre elas o Google Classroom, por meio da qual nos intervalos entre cada encontro, foram disponibilizados materiais para estudo e atividades mobilizadoras em diferentes formatos, para facilitar a compreensão dos alunos sobre temas importantes para o desenvolvimento das atividades.

\section{Análise dos Resultados}

A análise foi realizada com base nas 3 (três) categorias de análise que consistem nas funções do sistema atencional: Controle, Seleção e Vigilância.

Iniciamos com uma visão geral dos dados produzidos por meio das observações realizadas nos encontros. É possível perceber, com base no Gráfico 1, que a categoria de análise Seleção foi a que teve maior número de manifestações observadas, seguida das categorias Controle e Vigilância com menor número.

\section{Gráfico 1: Manifestações por Categoria de Análise}


DOI: $10.12957 /$ teias. $\%$ Y.55758

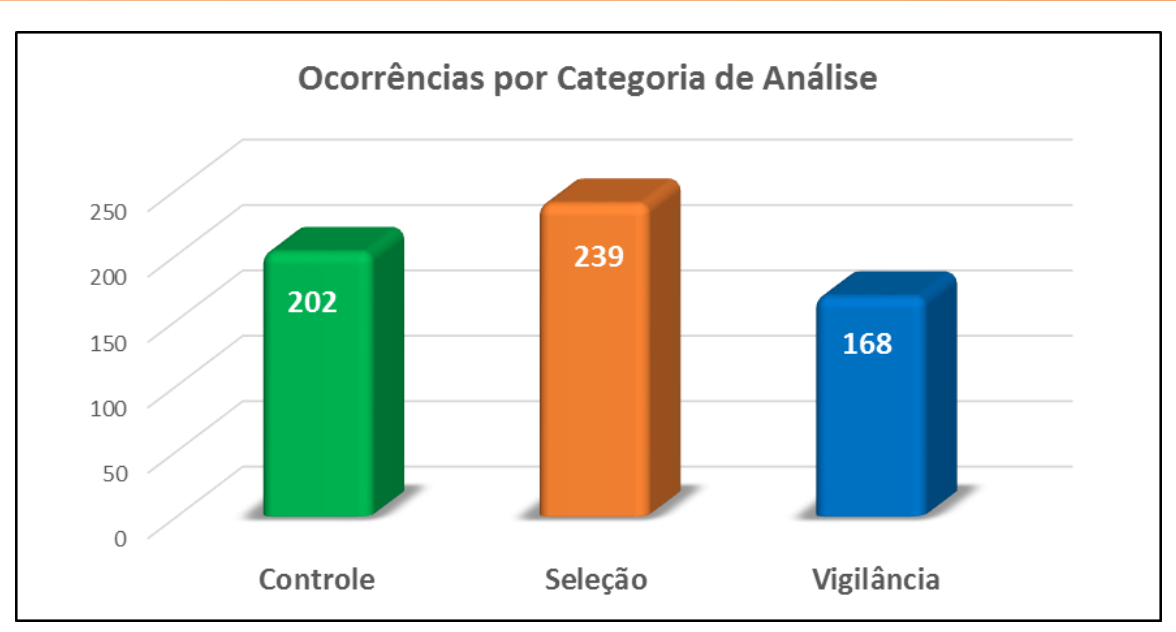

Fonte: autores (2020).

A função de Seleção funciona como um filtro, ou seja, diante da grande quantidade de estímulos a que somos submetidos a cada instante selecionamos somente uma parte para focalizarmos nossa atenção. Percebemos que a metodologia utilizada para a realização da intervenção pedagógica teve influência no maior número de manifestações da função de Seleção, pois as atividades desenvolvidas com base na abordagem Design Thinking permitiram a variação de técnicas de aprendizagem que, conforme percepção dos alunos, tornaram os encontros interativos e com atividades diversificadas.

A categoria de análise Controle também teve um número expressivo de manifestações. Ao explicar o controle dos recursos atencionais limitados, Pozo (2008) faz a distinção entre processos automáticos e controlados, respectivamente, sem e com atenção. A abordagem Design Thinking que guiou as atividades da pesquisa favorece a manifestação de processos controlados que exigem concentração, por envolver o estudante ativamente em tarefas que são diferentes a cada fase do processo, desde identificar um desafio até prototipar a solução.

A função de vigilância é a responsável pela atenção contínua, que nos mantém atentos e alertas, concentrados em uma atividade por períodos longos, esta foi a categoria que mostrou um número menor de manifestações. Conforme Pozo, "manter a atenção pode ser uma tarefa bem difícil, especialmente quando a atividade requer uma atenção contínua prolongada, como acontece com a maior parte das aprendizagens complexas". (2008, p. 150). Segundo o autor, crianças e jovens são menos capazes de manter a atenção, por isso necessitam de tarefas mais curtas e que variam com muita frequência.

Para possibilitar uma análise mais específica dos resultados obtidos, faremos a seguir um exame detalhado sobre cada categoria de análise, a partir dos dados produzidos por meio dos instrumentos: observação, questionário e grupo focal.

\section{Gráfico 2: Categoria de Análise Controle}




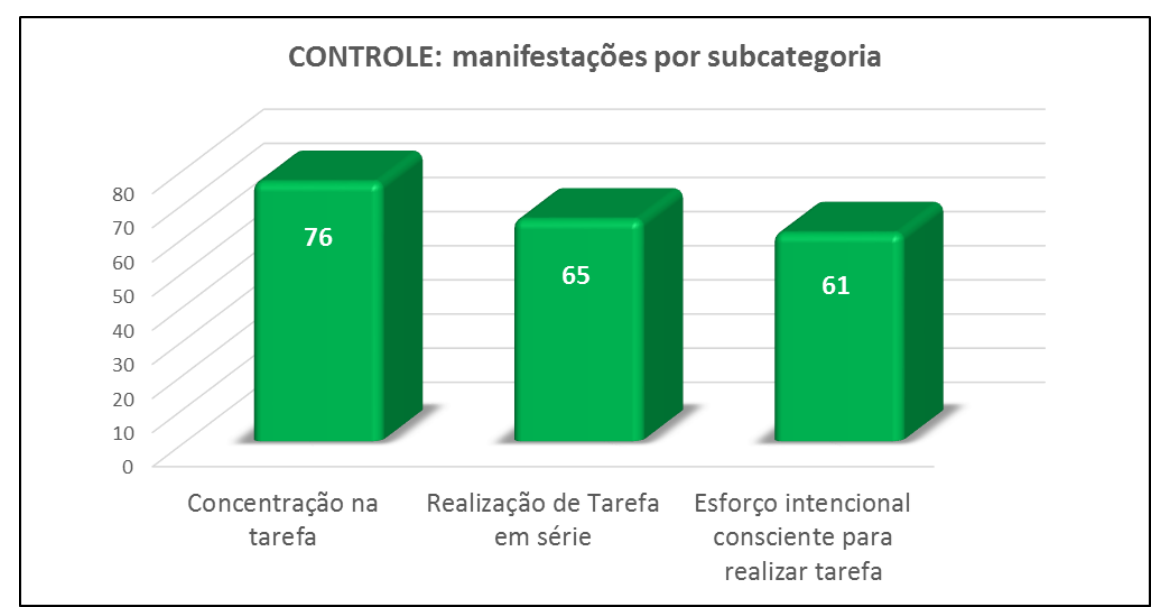

Fonte: autores (2020).

As principais características dos processos controlados, segundo Sternberg (2008), são a concentração para realização de tarefas, a realização de tarefas em série e o esforço intencional consciente para realizar as tarefas, que são as subcategorias de análise apresentadas no Gráfico 2. Analisando o gráfico percebemos um número maior de manifestações das subcategorias Concentração na tarefa e Realização de tarefa em série.

\section{Gráfico 3: Subcategoria de Análise Realização de tarefa em série}

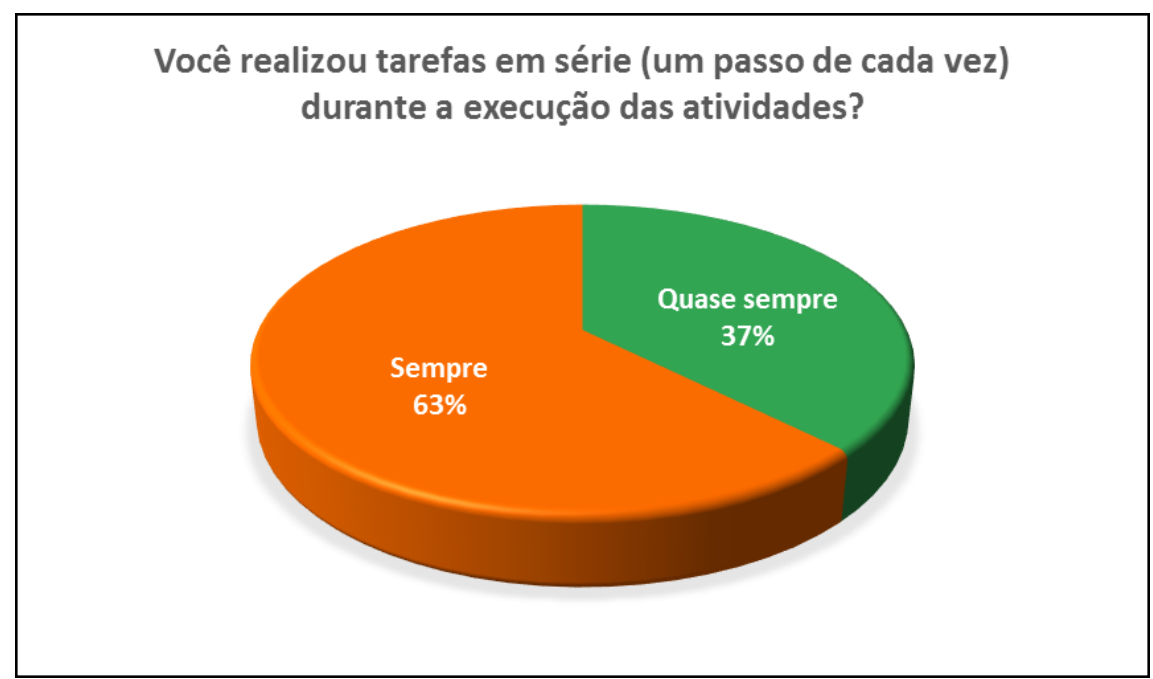

Fonte: autores (2020).

O Gráfico 3 mostra que os estudantes percebem ter realizado tarefas em série sempre ou quase sempre durante a realização do projeto. Podemos perceber que o uso do Design Thinking contribuiu para a realização das tarefas em série de forma sequencial. Devido à própria natureza da abordagem, que sugere realizar o processo de forma incremental dividido em fases, foi possível ao longo do projeto propor a realização de diferentes atividades, com objetivos e resultados distintos.

Ao analisar no Gráfico 2 o Esforço intencional consciente para realizar tarefa, percebemos que a maioria dos estudantes relatou ter realizado esforço mental para realização das atividades somente 
às vezes. No entanto, o instrumento Grupo Focal permitiu identificar que houve maior esforço mental para realização das atividades na fase de Experimentação do Design Thinking.

A categoria de análise Seleção busca identificar as manifestações que indicam o direcionamento da atenção dos alunos para as atividades propostas. São vários os fatores implícitos que podem influenciar na escolha e no direcionamento da atenção, entre eles: relevância, interesse, preferência, necessidade, relação com experiências anteriores e novidade. Com base nesses elementos foram definidas as subcategorias de análise apresentadas no Gráfico 4.

Gráfico 4: Categoria de Análise Seleção

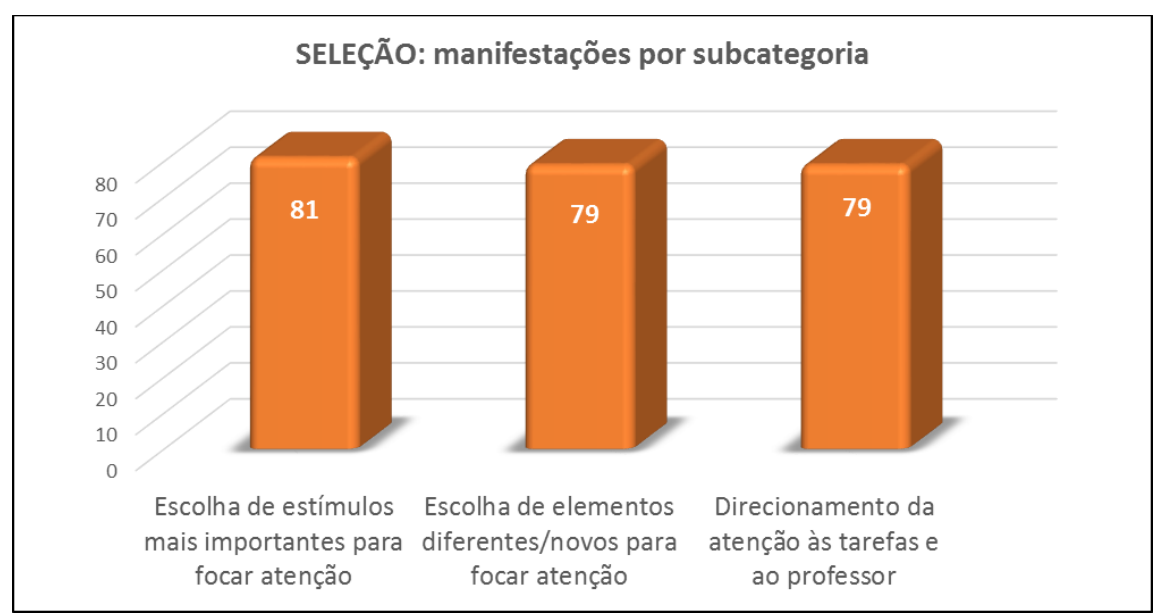

Fonte: autores (2020).

Percebemos, em comparação com a categoria controle, um número expressivo de manifestações e muito semelhante nas três subcategorias. Também é possível observar que a maioria dos estudantes acredita ter direcionado sua atenção para as atividades por achá-las diferentes e inovadoras, conforme nos mostra o Gráfico 5.

Nesta subcategoria percebemos influência direta das escolhas metodológicas, sendo que a população da pesquisa nunca havia tido aulas mediadas usando a proposta da Sala de Aula Invertida ou a abordagem Design Thinking, o que gerou curiosidade por serem formas diferentes de aprender. A necessidade de realizar as atividades no formato totalmente remoto também teve influência nessa percepção.

O uso de técnicas variadas de aprendizagem ativa, apoiadas por diferentes ferramentas digitais, parece ter influenciado o direcionamento da atenção dos estudantes. O resultado vai ao encontro do princípio elencado por Pozo (2008, p. 150) no qual sugere "diversificar as tarefas de aprendizagem, mudando o formato e envolvendo ativamente os alunos na execução das mesmas".

Gráfico 5: Subcategoria Escolha de elementos diferentes/novos para focar atenção 


\section{Você direcionou sua atenção para as atividades propostas por achá-las diferentes e inovadoras em comparação com as desenvolvidas nas aulas convencionais?}

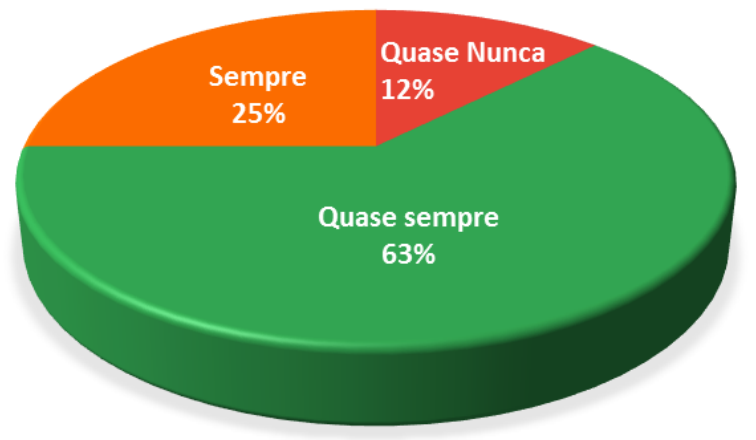

Fonte: autores (2020).

Os resultados do questionário corroboram a percepção inicial, apresentada no Gráfico 4. Pois mostra influência similar e relevante das 3 subcategorias de análise correspondentes à função de Seleção, no sentido de despertar a atenção dos alunos para as atividades desenvolvidas usando a abordagem Design Thinking.

Na categoria de análise Vigilância buscamos identificar as manifestações que evidenciam a atenção contínua, situação que mantém os alunos atentos e alertas, concentrados em uma atividade por longo período. A partir desses elementos foram definidas as subcategorias de análise apresentadas no Gráfico 6.

Gráfico 6: Categoria de Análise Vigilância

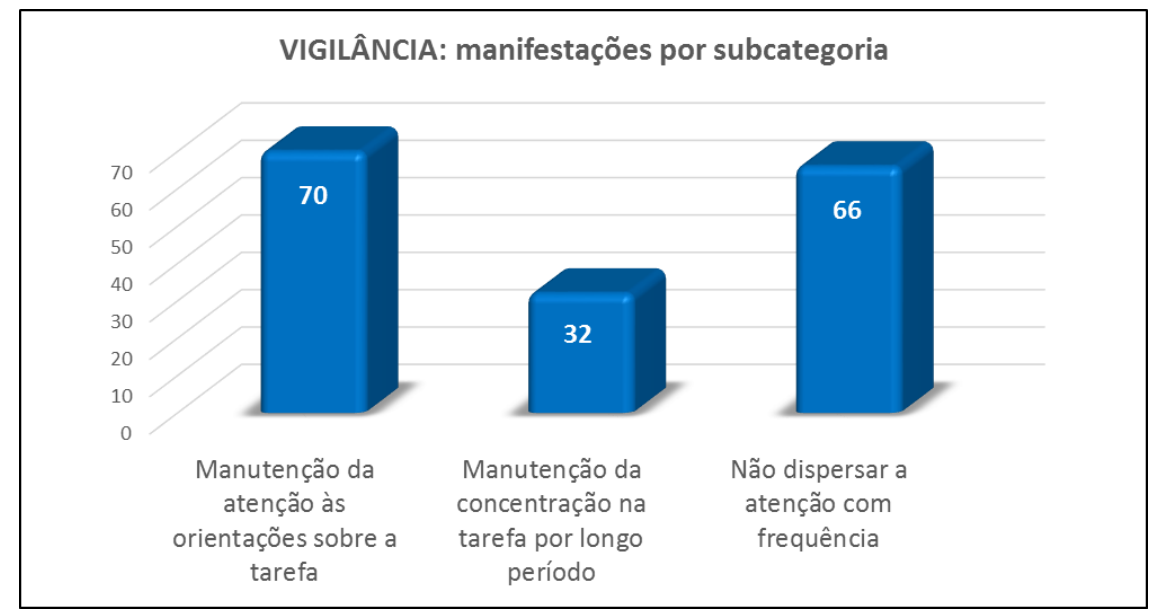

Fonte: autores (2020).

Analisando o Gráfico 6 percebemos um número maior de manifestações das subcategorias Manutenção da atenção às orientações sobre a tarefa e Não dispersar a atenção com frequência. O número menor de manifestações da subcategoria Manutenção da concentração na tarefa por longo período confirma o alerta de Pozo (2008) sobre a dificuldade dos jovens para manter a atenção contínua prolongada. 
Gráfico 7: Subcategoria Manutenção da concentração na tarefa por longo período

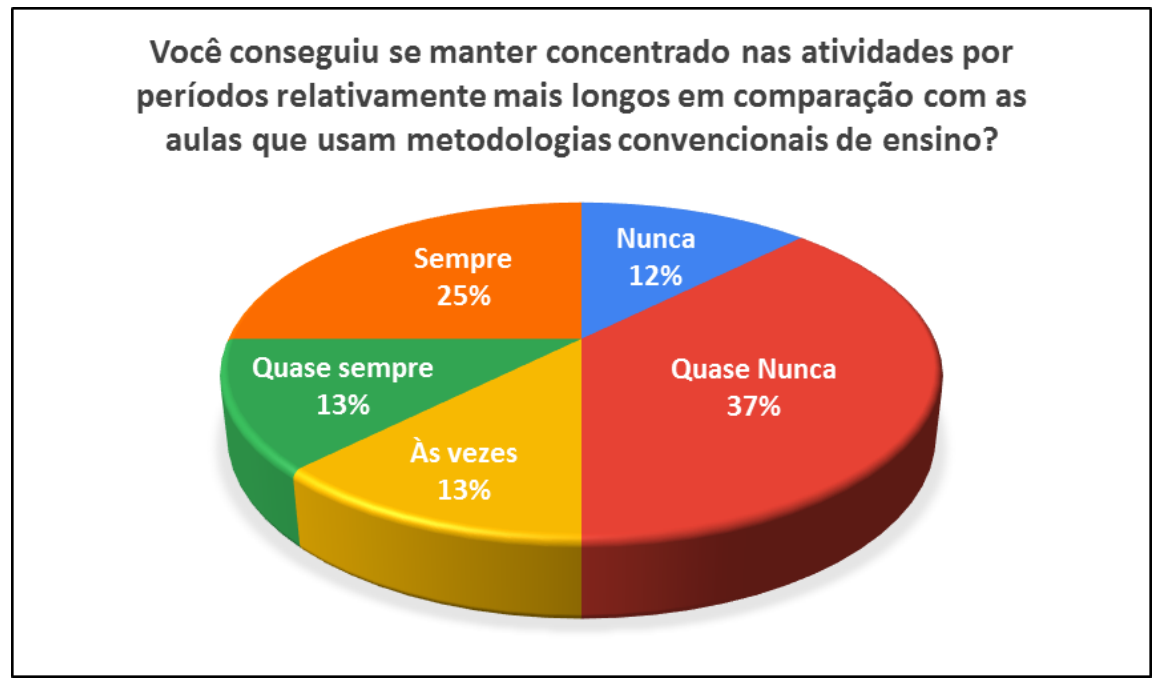

Fonte: autores (2020).

O Gráfico 7 mostra que a maioria dos alunos admitiu não conseguir manter a concentração na tarefa durante períodos mais longos, sendo que apenas $38 \%$ conseguiram manter a concentração sempre ou quase sempre. À vista disto, é importante lembrar que de acordo com os estudos de Sternberg (2008), a vigilância, de forma eficiente e sem perda de desempenho, dura em torno de trinta minutos.

Entretanto, também foi possível perceber que houveram manifestações dessa subcategoria em momentos de aprendizagem assíncronas, quando os alunos estavam mais engajados nas atividades, em especial na fase de Experimentação do Design Thinking, conforme as respostas dos alunos ao questionamento realizado no Grupo Focal: "Lembra ter ficado concentrado em atividade realizada individualmente ou em grupo por longo período (30 minutos ou mais)?"

Aluno A: "Sim, principalmente na hora de pensar o projeto e como desenvolvê-lo";

Aluno B: "Ao utilizar o Figma 1 para elaborar o protótipo do aplicativo acabei passando cerca de 2 duas horas ou mais conversando e elaborando o protótipo sem perceber";

Aluno C: "Sim! Na hora de fazer o infográfico no Canva".

O fato da função de vigilância ter se manifestado em momentos de aprendizagem autônoma dos alunos corrobora a percepção de Pozo (2008, p. 150), quando diz que "para minimizar esta dificuldade em manter atenção é importante que os estudantes tenham toda a autonomia possível para realização de tarefas, isto vai possibilitar que estabeleçam seu próprio ritmo de aprendizagem e se envolvam mais ativamente".

Ao sintetizar os resultados referentes à categoria Vigilância identificamos uma relação direta entre as subcategorias Não dispersar a atenção com frequência e Manutenção da concentração na tarefa por longo período, desse modo evidenciamos que quanto mais longas e exaustivas forem as atividades maiores são as chances de os alunos dispersarem a atenção.

Para além dos resultados já apresentados a partir das categorias de análise, julgamos importante identificar as contribuições da abordagem Design Thinking para as manifestações das

\footnotetext{
${ }^{1}$ Figma é um editor gráfico de vetor e prototipagem de projetos de design baseado em navegador web.
} 
funções do Sistema Atencional. Para tanto, apresentamos a seguir dados que nos ajudam a identificar tais contribuições.

Cada fase do Design Thinking sugere a realização de múltiplas atividades ocasionando diferentes influências sobre a ativação das funções do Sistema Atencional. O Gráfico 8 mostra as manifestações de cada categoria de análise observadas em cada fase do Design Thinking. Assim, percebemos que o nível de ativação de cada função (controle, seleção e vigilância) foi diferente em cada fase da abordagem.

\section{Gráfico 8: Categorias de Análise x Fases Design Thinking}

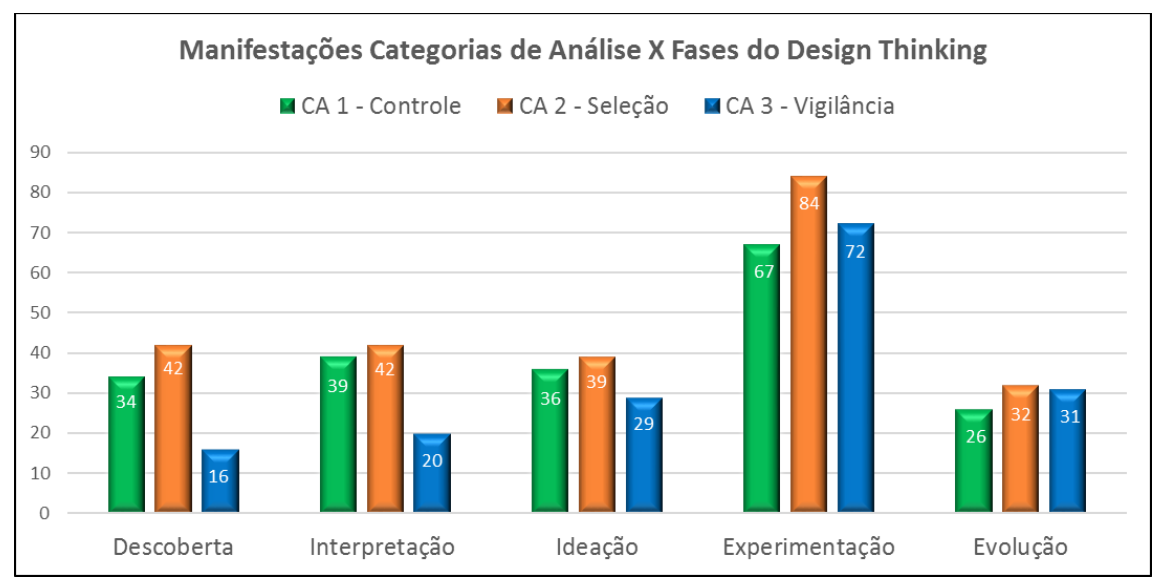

Fonte: autores (2020).

Ao analisar o Gráfico 8 observamos que em todas as fases a categoria de análise Seleção teve maior número de manifestações, confirmando a percepção de que a novidade e a diversidade de tarefas, que teve influência para atrair a atenção dos estudantes se manteve ao longo das fases.

Identificamos um número maior de manifestações de todas as categorias de análise na fase de Experimentação, quando ocorreu a construção dos protótipos da solução, por ser uma etapa de autoria e atividades práticas, que aumentaram o envolvimento dos estudantes.

De forma específica, na fase de Experimentação observamos aumento da Vigilância, com maior número de manifestações que a categoria Controle. Esse resultado corrobora a percepção de que o maior engajamento dos alunos nas atividades ocorre quando estes têm maior responsabilidade e autonomia, fazendo com que dediquem mais tempo contínuo para sua realização. Observando as ocorrências da categoria Vigilância, ilustradas no Gráfico 8, percebemos que foram aumentando conforme os encontros foram acontecendo, demonstrando o envolvimento gradativo dos alunos com o projeto.

\section{CONSIDERAÇÕES FINAIS}

Este estudo buscou analisar as manifestações das funções do Sistema Atencional em estudantes de ensino médio integrado do IFRS - Campus Sertão diante de processos educativos baseados em Metodologias Ativas de Aprendizagem, com o propósito de identificar as possíveis contribuições desta estratégia didática para despertar e manter a atenção dos estudantes.

A análise dos resultados tem como referência as três categorias de análise: Controle, Seleção e Vigilância, escolhidas com base nas funções do Sistema Atencional definidas por Pozo (2008). 
Ao término da pesquisa de campo, constatamos que a categoria de análise Seleção foi a que teve maior número de manifestações observadas nos encontros, seguida das categorias Controle e Vigilância com menor número. Esse resultado evidencia o potencial das metodologias ativas utilizadas na intervenção para atrair a atenção dos estudantes.

$\mathrm{Na}$ categoria Controle observamos um número considerável de manifestações, sendo a segunda categoria com maior número de ocorrências. Os estudantes perceberam estar mais concentrados e realizando tarefas em série durante a realização do projeto, em comparação com atividades realizadas em aulas convencionais. Sobre os resultados da categoria Vigilância merece destaque o fato de que houve aumento das manifestações dessa função em momentos que exigiram maior responsabilidade e autonomia por parte dos alunos para a realização das atividades.

Com os resultados obtidos também percebemos a combinação das metodologias Sala de Aula Invertida e Design Thinking como alternativa metodológica potente para a ativação do Sistema Atencional. Destacamos que a grande maioria dos alunos considerou a abordagem escolhida muito importante para seu envolvimento nas atividades propostas e mediadas, afirmando esta combinação metodológica como estratégia didática que potencializa a ativação das funções do Sistema Atencional em processos de aprendizagem.

Com base neste resgate do percurso da investigação e na síntese de seus resultados, respondemos a nossa questão norteadora da pesquisa da seguinte forma: As Metodologias Ativas de Aprendizagem Sala de aula Invertida e Design Thinking apresentaram relevante influência sobre a ativação das funções do Sistema Atencional de estudantes do $3^{\circ}$ ano do curso Técnico em Manutenção e Suporte em Informática. Com ênfase na função de Seleção, por despertar a atenção dos alunos, direcionando-a para atividades diferentes e interessantes. $\mathrm{Na}$ função de Controle destacou-se a contribuição para concentração e realização de tarefas em série. A influência na função de Vigilância foi menos percebida, porém, manifestou-se no engajamento dos estudantes com as atividades propostas, em especial, na fase de Experimentação do Design Thinking.

Ressaltamos que no contexto de isolamento social a realização das atividades da pesquisa empírica por meio dos encontros remotos foi muito desafiadora, mas também enriquecedora, tanto para a pesquisadora como para os estudantes. Contribuiu para o envolvimento em atividades educativas que permitiram experimentar novas possibilidades de aprendizagem indo ao encontro do cenário educacional imposto pela pandemia causada pelo novo coronavírus. Tal situação, em contexto de ensino remoto, evidenciou a importância das Metodologias Ativas de Aprendizagem, em especial, pela sua contribuição para atrair a atenção dos estudantes, ajudando a envolvê-los no processo de aprendizagem.

É importante considerar que os resultados apresentados foram obtidos em contexto e situação específicos de aprendizagem, assim, sabemos que a atenção não depende somente da metodologia utilizada. A forma como a mediação é conduzida e o fator novidade, entre outros, são elementos que também podem ter influência sobre a atenção dos estudantes.

Desse modo, a partir dos resultados que mostram as Metodologias Ativas de Aprendizagem como potencializadoras das funções do Sistema Atencional em contextos de aprendizagem presencial e remota, esperamos que este estudo possa contribuir para outras investigações sobre o uso de Metodologias Ativas nos processos educativos, como estratégias didáticas que estimulam a atenção e favorecem a aprendizagem de forma crítica e reflexiva, mostrando-se como importante alternativa neste cenário educacional desafiador que demanda, cada vez mais, novas formas de ensinar a aprender. 


\section{REFERÊNCIAS}

BACICH, Lilian; MORAN, José (Orgs.). Metodologias ativas para uma educaşão inovadora: uma abordagem teórico-prática. Porto Alegre: Penso Editora, 2018.

CHRISTENSEN, Clayton M., HORN, Michael B.; STAKER, Heather. Blended - Usando A Inovação Disruptiva Para Aprimorar A Educação. São Paulo: Penso Editora, 2015.

INSTITUTO EDUCADIGITAL. Design thinking para educadores. 2014. Disponível em:<https://www.designthinkingforeducators.com/DT_Livro_COMPLETO_001a090.pdf $>$.

Acesso em: 17 mai. 2019.

MORA, Francisco. Neuroeducación: Solo Se Puede Aprender Aquello Que Se Ama. Madrid: Alianza Editorial, 2013.

POZO, Juan Ignacio. Aprendizes e mestres: a nova cultura da aprendizagem. Trad. Ernani Rosa. Porto Alegre: Artmed. 2008.

ROCHA, Julciane. Design Thinking na formação de professores: novos olhares para os desafios da educação. In: BACICH, Lilian; MORAN, José (Orgs.). Metodologias ativas para uma educação inovadora: uma abordagem teórico-prática. Porto Alegre: Penso Editora, 2018.

STERNBERG, Robert J. Psicologia Cognitiva. Trad. Roberto Cataldo Costa. 4 ed. Porto Alegre: Artmed, 2008.

Submetido em novembro de 2020 Aprovado em abril de 2021

\section{Informações dos autores}

Cheila Graciela Gobbo Bombana

Professora do Instituto Federal de Educação, Ciência e Tecnologia do Rio Grande do Sul (IFRS)

Mestre em Educação pela Universidade de Passo Fundo (UPF)

E-mail: cheila.bombana@sertao.ifrs.edu.br

ORCID: https://orcid.org/0000-0002-8882-0200

Link Lattes: http://lattes.cnpq.br/5124982427107491

Adriano Canabarro Teixeira

Professor Titular da Universidade de Passo Fundo (UPF)

Doutor em Informática na Educação pela Universidade Federal do Rio Grande do Sul (UFRGS)

E-mail: teixeira@upf.br

ORCID: https://orcid.org/0000-0003-3052-6970

Link Lattes: http://lattes.cnpq.br/1841882790688813 